\title{
Detection of Heavy Metal Ions in Aqueous Solution Using Direct Dye Chemosensors
}

\author{
Eun-Yeong Heo, Young-Il Ko and Jin-Seok Bae ${ }^{\dagger}$ \\ Department of textiles system engineering, Kyungpook national universty \\ 1370 sangyeok-dong, Buk-gu, Daegu, 702-701, KOREA
}

(Received: September 25, 2009/Revised: October 20, 2009/Accepted: October 22, 2009)

\begin{abstract}
Since heavy metal pollution is a significant global environmental problem and very dangerous to human health, the improved methods for detecting heavy metals are required recently. Colorimetric chemosensors are now considered as one of the most effective analytical method used in the environment monitoring. New direct dyes having the function of colorimetric chemosensors were synthesized. When metal ions such as $\mathrm{Al}^{3+}, \mathrm{Ca}^{2+}, \mathrm{Cd}^{2+}, \mathrm{Cr}^{3+}, \mathrm{Cu}^{2+}, \mathrm{Fe}^{2+}, \mathrm{Fe}^{3+}, \mathrm{Hg}^{2+}, \mathrm{Li}^{+}$, $\mathrm{Mg}^{2+}, \mathrm{Na}^{+}, \mathrm{Ni}^{2+}, \mathrm{Pb}^{2+}$ and $\mathrm{Zn}^{2+}$ were added each solution of new direct dyes, the color of solution was changed and can be easily detected with naked eyes without expensive experimental equipment such as atomic absorption spectrometer (AAS) or inductively coupled plasma-mass spectrometer (ICP-MS). The new benzidine analogues were diazotized and reacted with couplers such as H-acid, J-acid, Chromotropic acid, Nevill-winther acid and gamma acid to synthesize new direct dyes. The structures of the new direct dyes were confirmed by high resolution mass spectrometer (FAB ionization) and evaluated with UV-Vis spectroscopy. The UV-VIS spectroscopy was measured for the dye solutions by adding various concentrations of metal ions. It was observed that the absorbance in UV-Vis spectra was changed as the heavy metal ions were added.
\end{abstract}

Keywords: chemosensor, heavy metals, colorimetric sensor, direct dye, benzidine analogue

\section{Introduction}

Colorimetric chemosensors are now recognized as the valid analytical method used in the process control, environmental and biomedical monitoring ${ }^{1-3)}$. Recently, several colorimetric probes, so-called "naked eye chemosensors", have been developed for the detection of small quantities of heavy metals. The detection of heavy metal ions is of particular significance due to the toxic impact on the environment ${ }^{4-6}$. Heavy metal ion pollution poses severe risks for human health and the environment. Mercury contamination is widespread and occurs from a variety of natural sources ${ }^{7)}$.

Heavy metal ion is well known pollutant for environment and human health because it is transferred through several medium. Once come into body, heavy metal is piled up in our body binding with protein and causes side effects for a long time.
Heavy metal in our body is very dangerous because it causes a lot of side effects. For example, lead $(\mathrm{Pb})$ anesthetizes muscle and the nerve system of our body. Cadmium (Cd) causes lung cancer and weakens the bone. Manganese (Mn) affects growth and reproduction system. Also, Minamata disease which is representative of heavy metal pollutant appears tremor of the legs, arms, and tongue, progressive walking asynergia, and phono logical disorder, and so on. This disease is caused by mercury poisoning. Recently, there are lot of reports about heavy metal pollutant in domestic. Atopic dermatitis and bronchial asthma appears because of heavy metal pollutant.

The equipments such as atomic absorption spectrometer (AAS) and inductively coupled plasma - mass spectrometer (ICP-MS) have been used to detect heavy metal ${ }^{8-9)}$. However this equipments is spend time, cost, and human power ${ }^{10)}$. Also, if the sample is not appropriately pretreated, the result of

${ }^{\dagger}$ Corresponding author. Tel: +82-53-950-7281; Fax: +82-53-950-6617; e-mail: jbae@knu.ac.kr 
sample occurs error. Selective optical sensing is attracting strong interest due to the use of "low-tech" spectroscopic instrumentation to detect relevant chemical species in biological and environmental processes. In particular, one aspect of environmental monitoring is the detection of low levels of heavy metals in aqueous solutions.

In this study, new direct dyes were synthesized to detect heavy metals easily with naked eyes instead of expensive and time consuming equippments. The color changes of dyes were observed by dropping each heavy metal in solution. The changes of absorbance was quantitative analyzed using UV-VIS spectroscopy.

\section{Experimental}

\subsection{Synthesis of 4-methyl-2-nitropropoxy- benzene}

4-Methyl-2-nitrophenol $(53.6 \mathrm{~g}, 0.35 \mathrm{~mol})$ and 2methoxyethanol $(135 \mathrm{~mL})$ were placed in a $500 \mathrm{~mL}$ round bottom flask. 1-Bromopropane (64.6g, $0.525 \mathrm{~mol}$ ) and anhydrous $\mathrm{K}_{2} \mathrm{CO}_{3}(48.4 \mathrm{~g}, 0.35 \mathrm{~mol})$ were added with vigorous stirring. The deep red mixture was stirred under a reflux $\left(105-110^{\circ} \mathrm{C}\right)$ for $6 \mathrm{~h}$ and then TLC showed only one product, $\mathrm{R}_{\mathrm{f}}=0.54$ (PhMe:hexane=4:1). The yellow/brown mixture was allowed to cool, filtered, and the collected solid was washed with EtOAc. The combined washings and filtrate were transferred to a rotary evaporator where the solvent was removed. The dark brown crude liquid was dissolved in EtOAc $(475 \mathrm{~mL})$ and the solution was washed twice with $5 \% \mathrm{NaOH}$ $(55 \mathrm{~mL})$, and twice with water $(50 \mathrm{~mL})$. The organic layer was transferred to a rotary evaporator where the solvent was removed. The dark brown oil was distilled to give $65.3 \mathrm{~g}$ (96\%) of yellow liquid, bp $118^{\circ} \mathrm{C}(2-3 \mathrm{~mm} \mathrm{Hg})$.

\subsection{Synthesis of 2-nitropropoxybenzene}

The synthesis of 2-nitropropoxybenzene was carried out using 2-nitrophenol $(46.8 \mathrm{~g}, 0.3 \mathrm{~mol})$ and the procedure described above for 4-methyl-2-nitropropoxybenzene. The synthesis gave $45.2 \mathrm{~g}$ (82\%) product, $\mathrm{R}_{\mathrm{f}}=0.5$.

\subsection{Synthesis of 2,2'-dimethyl-5,5'-dipropox- ybenzidine}

4-Methyl-2-nitropropoxybenzene (100g, $0.51 \mathrm{~mol})$ and ligroine $(100 \mathrm{~mL})$ were placed in a $500 \mathrm{~mL}$ round bottom flask. To this yellow solution was added zinc dust $(100.5 \mathrm{~g}, 1.54 \mathrm{~mol})$ with vigorous stirring. The mixture was stirred at $70-80^{\circ} \mathrm{C}$, as $50 \%$ $(\mathrm{w} / \mathrm{w}) \mathrm{NaOH}(7.2 \mathrm{~g}, 0.09 \mathrm{~mol})$ was added dropwise over $1 \mathrm{~h}$. Water $(6.5 \mathrm{~g}, 0.36 \mathrm{~mol})$ was then added dropwise over $1 \mathrm{~h}$, also at $70-80^{\circ} \mathrm{C}$.

The color of the mixture gradually changed from yellow to orange to red. After about $12 \mathrm{~h}, 20$ $\%$ more zinc was added and the mixture was stirred until the organic layer turned to colorless (approximately $3 \mathrm{~h}$ ).

TLC (PhMe:hexane $=4: 1)$ was used to follow the course of reaction, with the colorless product having $\mathrm{R}_{\mathrm{f}}=0.4$.

The reaction mixture was diluted by the addition of ligroine $(500 \mathrm{~mL})$, filtered, and the filtrate was allowed to cool. The organic layer was then washed twice with $1 \% \mathrm{HCl}(100 \mathrm{~mL})$, to remove by-products, and twice with water $(100 \mathrm{~mL})$.

The benzidine rearrangement was effected by the dropwise addition of $15 \% \mathrm{HCl}(187 \mathrm{~g}, 0.77 \mathrm{~mol})$ to the vigorously stirred organic layer, at $20^{\circ} \mathrm{C}$, over $40 \mathrm{~min}$. The mixture was stirred for $1 \mathrm{~h}$ and the precipitate was collected by filtration. The crude 2,2'-dimethyl-5,5'-dipropoxybenzidine dihydrochloride was repeatedly slurried with acetone and filtered, until a white product was obtained. The product was dried and recrystallized from $\mathrm{MeOH} / \mathrm{EtOAc}$ mixture to give $37.5 \mathrm{~g}$ (37\%) of 2,2'-dimethyl-5,5'dipropoxybenzidine dihydrochloride.

To prepare the free base, the 2,2'-dimethyl-5,5' dipropoxybenzidine dihydrochloride $(12 \mathrm{~g}, 0.03 \mathrm{~mol})$ was slurried with water $(100 \mathrm{~mL})$, neutralized by the dropwise addition of $5 \% \mathrm{NaOH}(47.8 \mathrm{~g})$ and the precipitate was extracted into EtOAc $(200 \mathrm{~mL})$. The organic layer was collected, washed with distilled water $(200 \mathrm{~mL})$, and dried over magnesium sulfate. EtOAc was then removed at the rotary evaporator to give $8.1 \mathrm{~g}$ (83\%), m.p. $=136^{\circ} \mathrm{C}$. TLC: $\mathrm{R}_{\mathrm{f}}=0.63(\mathrm{PhMe}: \mathrm{EtOAc}=3: 1)$ 

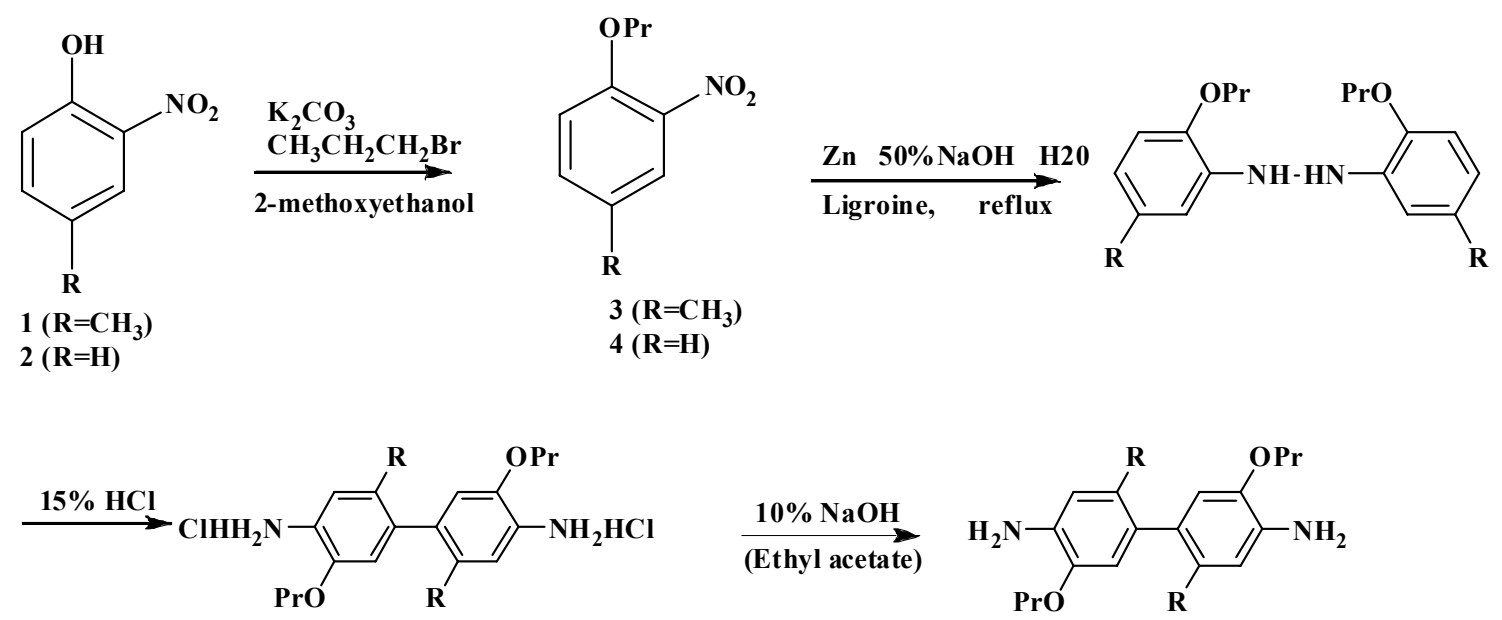

$5\left(\mathbf{R}=\mathbf{H}, \mathrm{CH}_{3}\right)$

$$
\begin{aligned}
& \mathbf{6}\left(\mathrm{R}=\mathrm{CH}_{3}\right) \\
& 7(\mathrm{R}=\mathrm{H})
\end{aligned}
$$

\section{$\mathbf{R}=\mathbf{H}: 5,5^{\prime}$-dipropoxybenzidine}

CH3 : 2,2'-dimethyl-5,5'-dipropoxybenzidine

Fig. 1. Synthesis of 2,2'-dimethyl-5,5'-dipropoxybenzine and 5,5'-dipropoxybenzine.

\subsection{Synthesis of 5,5'-dipropoxybenzidine}

The synthesis of 5,5'-dipropoxybenzidine was carried out using 2-nitropropoxybenzene $(92 \mathrm{~g}, 0.51 \mathrm{~mol})$ and the procedure described above for 2,2'dimethyl-5,5'-dipropoxybenzidine.

The synthesis gave 33g (22\%) product, m.p. = $138^{\circ} \mathrm{C}$. TLC: $\mathrm{R}_{\mathrm{f}}=0.6$ (PhMe:EtOAc $=3: 1$ )

Benzidine derivatives 6 and 7 were synthesized according to the steps shown in Fig. 1.

\subsection{Synthesis of Dyes}

2,2'-Dimethyl-5,5'-dipropoxybenzidine (1.41g, $43 \mathrm{mmol})$ and 5,5 '-dipropoxybenzidine $(1.3 \mathrm{~g}, 43 \mathrm{mmol})$ were dispersed separately in water $(8 \mathrm{~mL})$ containing $5 \mathrm{~g}$ ice and a mixture of conc. $\mathrm{HCl}(3 \mathrm{~mL})$ and $\mathrm{H}_{2} \mathrm{O}(4 \mathrm{~mL})$ was added. The temperature was cooled to $0-5^{\circ} \mathrm{C}$ in an ice bath, and $\mathrm{NaNO}_{2}(0.59 \mathrm{~g}$, $0.0086 \mathrm{~mol})$ dissolved in water $(5 \mathrm{~mL})$ was added dropwise with stirring over 30min. Sulfamic acid was added to destroy excess nitrous acid.

Activated carbon (10mg) was added with stirring and the mixture was filtered while maintaining the temperature at $0-5^{\circ} \mathrm{C}$. The clear yellow diazonium salt solution was added to the solution of coupler very slowly with stirring at $0-5^{\circ} \mathrm{C}$.

The couplers used to make direct dyes were $\mathrm{J}$-acid (2.21g, 86mmol), Chromotropic acid (2.75g, 86mmol), H-acid (2.94g, 86mmol), Neville-Winther acid (2.12g, $86 \mathrm{mmol})$, Naphthionic acid $(1.92 \mathrm{~g}, 86 \mathrm{mmol})$, and Gamma acid (2.21g, 86mmol).

These couplers were dissolved in water $(35 \mathrm{~mL})$ and an adjustment to $\mathrm{pH}$ 8-9 was conducted using very dilute $\mathrm{NaOH}$ solution. Coupling was continued for about $3 \mathrm{~h}$ at room temperature and the dyes were precipitated by adding $\mathrm{NaCl}(10-15 \mathrm{~g})$.

The precipitate was collected by filtration and dried. Dye purity was confirmed by TLC using BuOH: EtOH: $\mathrm{NH}_{4} \mathrm{OH}: \mathrm{H}_{2} \mathrm{O}$ (3:1:0.5:1.5) for dyes $8,9,14,16,17$ and (3:1:0.5:2.2) for dyes 10,11, $12,13,15$ as the eluent. The $R_{f}$ values were 0.45(8), 0.48(9), 0.47(10), 0.47(11), 0.47(12), 0.57(13), $0.38(14), \quad 0.57(15), 0.35(16)$, and $0.35(17)$. The structure of dyes synthesized are shown in Fig. 2.

We found that ESMS is an excellent method for confirming direct dye structures.

A summary of electrospray ionization mass spectrometry(ESMS) data recorded on dyes $8-17$ is shown in Table 1.

Data presented correspond to the analyte signals observed for $\mathrm{m} / 2, \mathrm{~m} / 3$ and $\mathrm{m} / 4$ species. As expected, dyes 8,9 and 14-17 gave only a m/2 signal, while dyes 10-13 gave signals arising from $2,3^{-}$and $4^{-}$charges. 
Table 1. Summary of ESMS data for the dyes prepared in this study

\begin{tabular}{cccc}
\hline Dye & $\mathbf{M} / \mathbf{2}$ Ions & $\mathbf{M} / \mathbf{3}$ Ions & $\mathbf{M} / \mathbf{4}$ Ions \\
\hline $\mathbf{8}$ & $413.3(2 \mathrm{Na})$ & & \\
$\mathbf{9}$ & $399.1(2 \mathrm{Na})$ & & \\
$\mathbf{1 0}$ & & $335.9(4 \mathrm{Na})$ & $246.3(4 \mathrm{Na})$ \\
$\mathbf{1 1}$ & $491.0(4 \mathrm{Na})$ & $327.2(4 \mathrm{Na})$ & $239.6(4 \mathrm{Na})$ \\
& & $319.6(3 \mathrm{Na}+\mathrm{H})$ & \\
$\mathbf{1 2}$ & & $336.5(4 \mathrm{Na})$ & $246.6(4 \mathrm{Na})$ \\
$\mathbf{1 3}$ & $479.0(4 \mathrm{H})$ & $319.0(4 \mathrm{H})$ & $239.4(4 \mathrm{H})$ \\
$\mathbf{1 4}$ & $398.0(2 \mathrm{Na})$ & & \\
$\mathbf{1 5}$ & $384.0(2 \mathrm{Na})$ & & \\
$\mathbf{1 6}$ & $413.3(2 \mathrm{Na})$ & & \\
$\mathbf{1 7}$ & $399.0(2 \mathrm{Na})$ & & \\
\hline
\end{tabular}

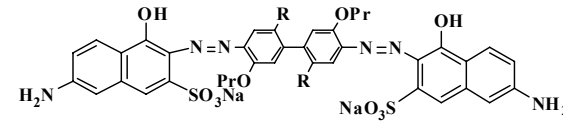

$8\left(\mathrm{R}=\mathrm{CH}_{3}\right)$$$
\mathrm{NH}_{2} \mathrm{OH} \quad \mathrm{OH} \quad \mathrm{OPr}
$$
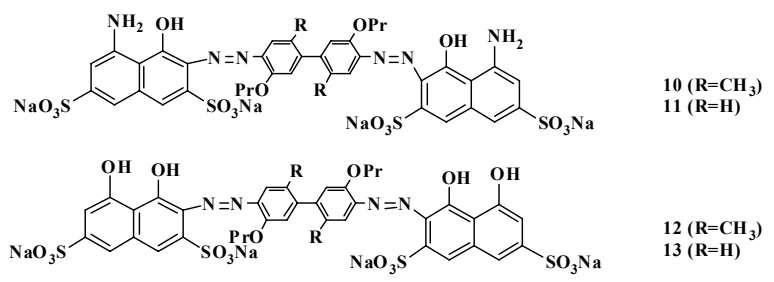

$12\left(\mathrm{R}=\mathrm{CH}_{3}\right)$

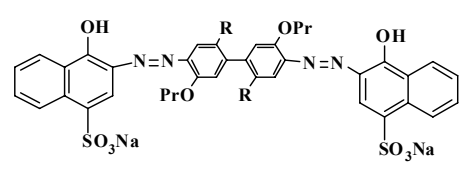

$14\left(\mathrm{R}=\mathrm{CH}_{3}\right)$
$15(\mathrm{R}=\mathrm{H})$

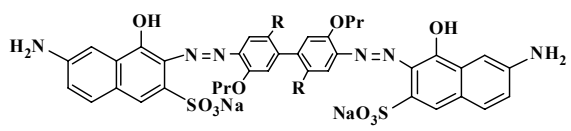

$16\left(\mathrm{R}=\mathrm{CH}_{3}\right)$
$17(\mathrm{R}=\mathrm{H})$

Fig. 2. Structures of direct dyes synthesized in this study.

\section{Results and Discussion}

The dyes synthesized were dissolved in water and then treated with a series of metal ions such as $\mathrm{Al}^{3+}$, $\mathrm{Ca}^{2+}, \mathrm{Cd}^{2+}, \mathrm{Cr}^{3+}, \mathrm{Cu}^{2+}, \mathrm{Fe}^{2+}, \mathrm{Fe}^{3+}, \mathrm{Hg}^{2+}, \mathrm{Li}^{+}, \mathrm{Mg}^{2+}$, $\mathrm{Na}^{+}, \mathrm{Ni}^{2+}, \mathrm{Pb}^{2+}$ and $\mathrm{Zn}^{2+}$. The color changes of each solutions were shown in Fig. 3 and 4.

For the dyes having methyl group, it is clearly shown that the colors were changed with $\mathrm{Al}^{3+}, \mathrm{Cu}^{2+}$, $\mathrm{Fe}^{3+}$ (or $\mathrm{Fe}^{2+}$ ) and rarely with $\mathrm{Hg}^{2+}$ and $\mathrm{Ni}^{2+}$. Especially, $\mathrm{Ni}^{2+}$ was detected in direct dye $\mathbf{1 0}$ having chromotropic acid. The colors of direct dyes which do not have methyl group was also changed due to the heavy metals. Overall, $\mathrm{Fe}^{3+}$ was detected for all of the dye solutions. For dye 9 having J-acid as coupler, many heavy metals such as $\mathrm{Al}^{3+}, \mathrm{Cr}^{3+}, \mathrm{Fe}^{2+}$, $\mathrm{Fe}^{3+}, \mathrm{Hg}^{2+}, \mathrm{Pb}^{2+}$ were detected. Especially, dye $\mathbf{1 5}$ having Neville-Winther acid showed color change only with $\mathrm{Fe}^{3+}$. The selectivity between dyes and heavy metals are shown in Fig. 5 and 6.

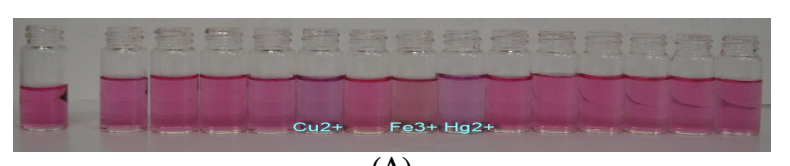

(A)

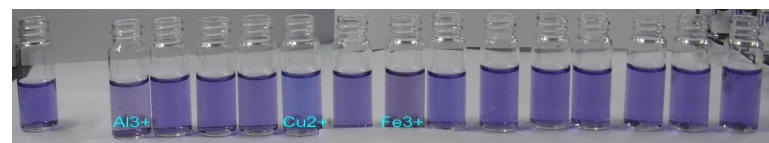

(B)

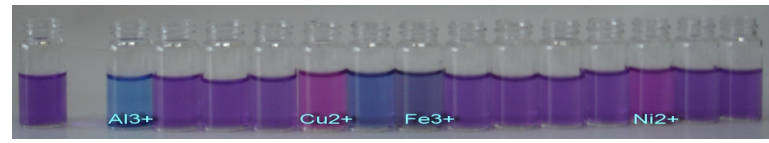

(C)

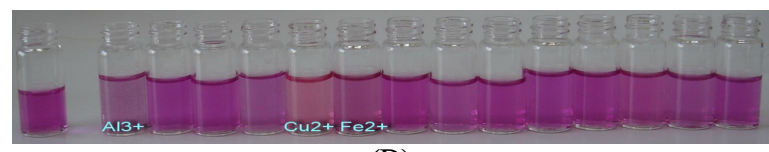

(D)

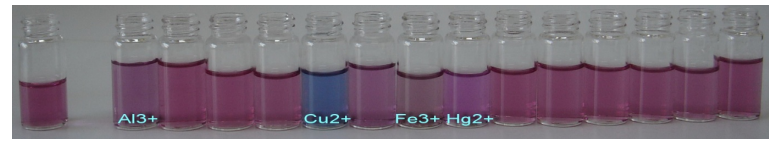

(E)

Fig. 3. T he color changes of dye solutions $(8,10,12$, $14,16)$.

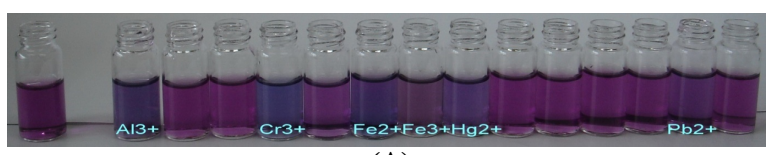

(A)

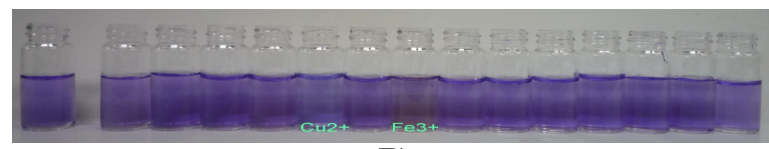

(B)

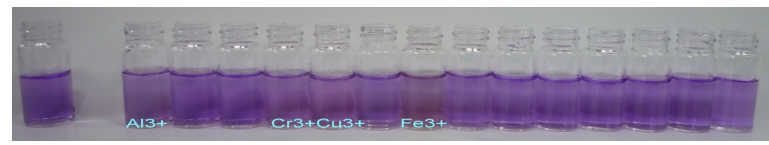

(C)

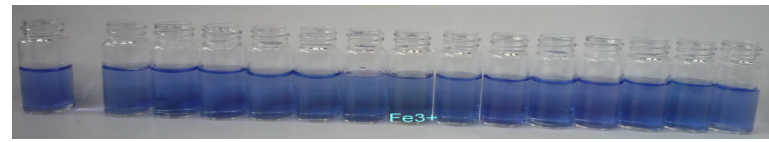

(D)

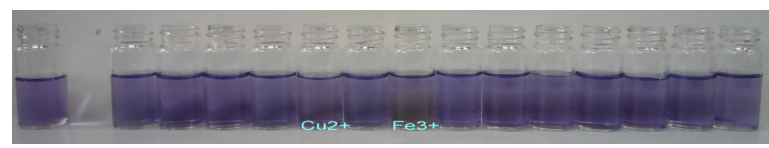

(E)

Fig. 4. The color changes of dye solutions $(9,11,13$, $15,17)$. 

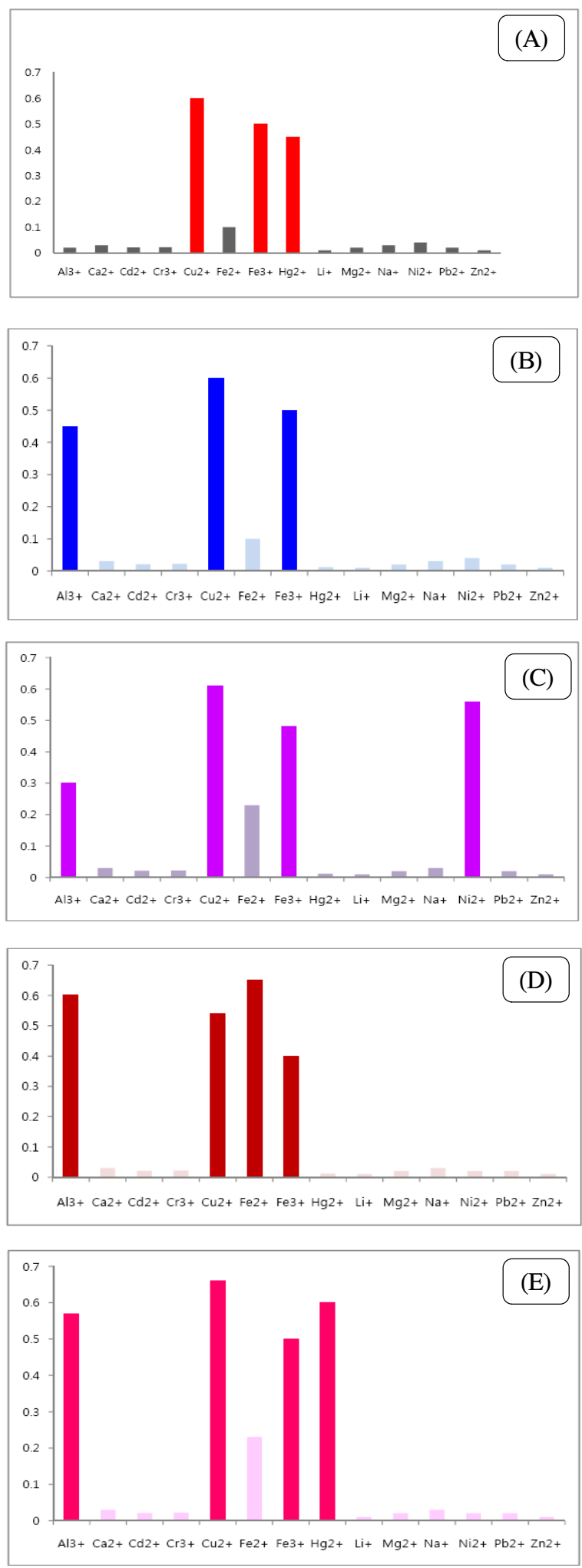

Fig. 5. The selectivity between dyes (8, 10, 12, 14, 16) and heavy metals.

The UV-Vis spectroscopy was measured with regard to heavy metal concentrations. The concentration of direct dye solutions $\left(10^{-4} \mathrm{M}\right)$ was same to the concentration of heavy
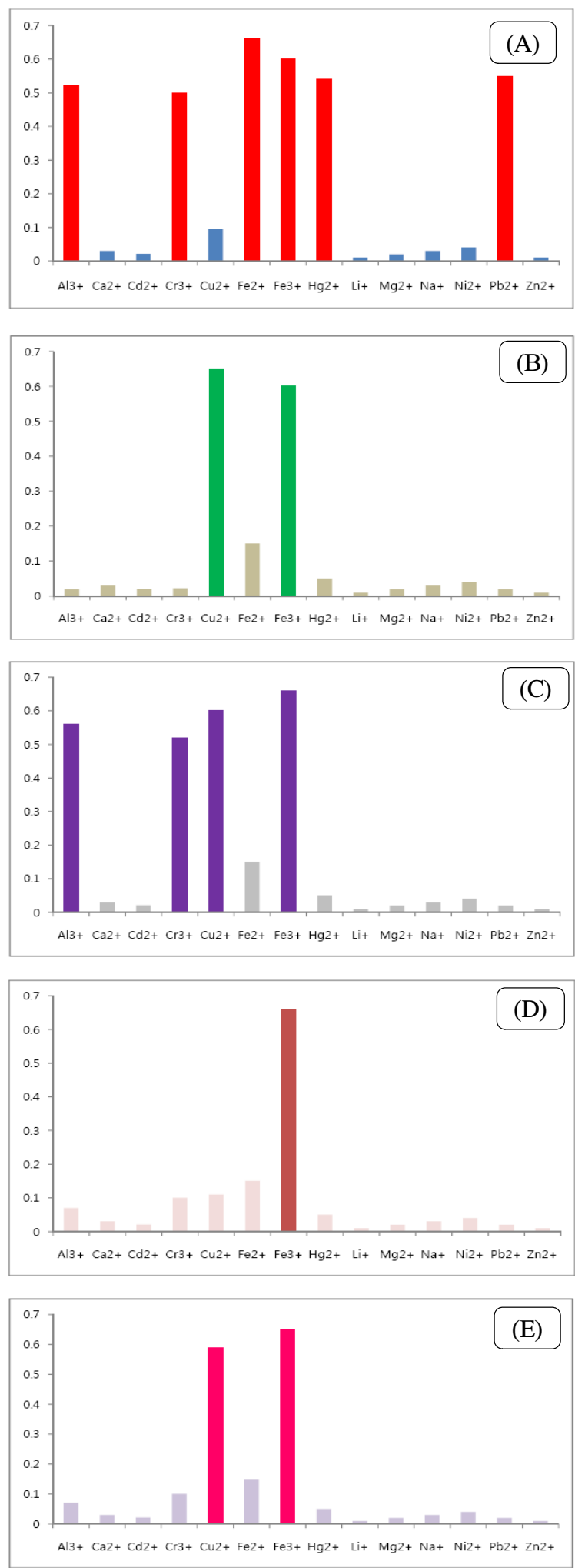

Fig. 6. The selectivity between dyes $(9,11,13,15$, 17) and heavy metals.

metal solutions $\left(10^{-4} \mathrm{M}\right)$. From 0.25 to $2.25 \mathrm{~mL}$ of $10^{-4} \mathrm{M}$ metal solutions were added in $1 \mathrm{~mL}$ of dyes respectively and total volume of solutions were adjusted to $10 \mathrm{~mL}$. 
Fig. 7 shows the changes on the UV-Visible spectra of dyes upon addition of several metals. As can be observed, the addition of metal ions induces a clear isosbestic point for some dyes or absorbance decreases for other dyes. From the molecular structure of dyes and spectral results, it is predicted that the addition of metal ions induces the ligand between hydroxy group and propoxy group as shown in Fig. 8 .
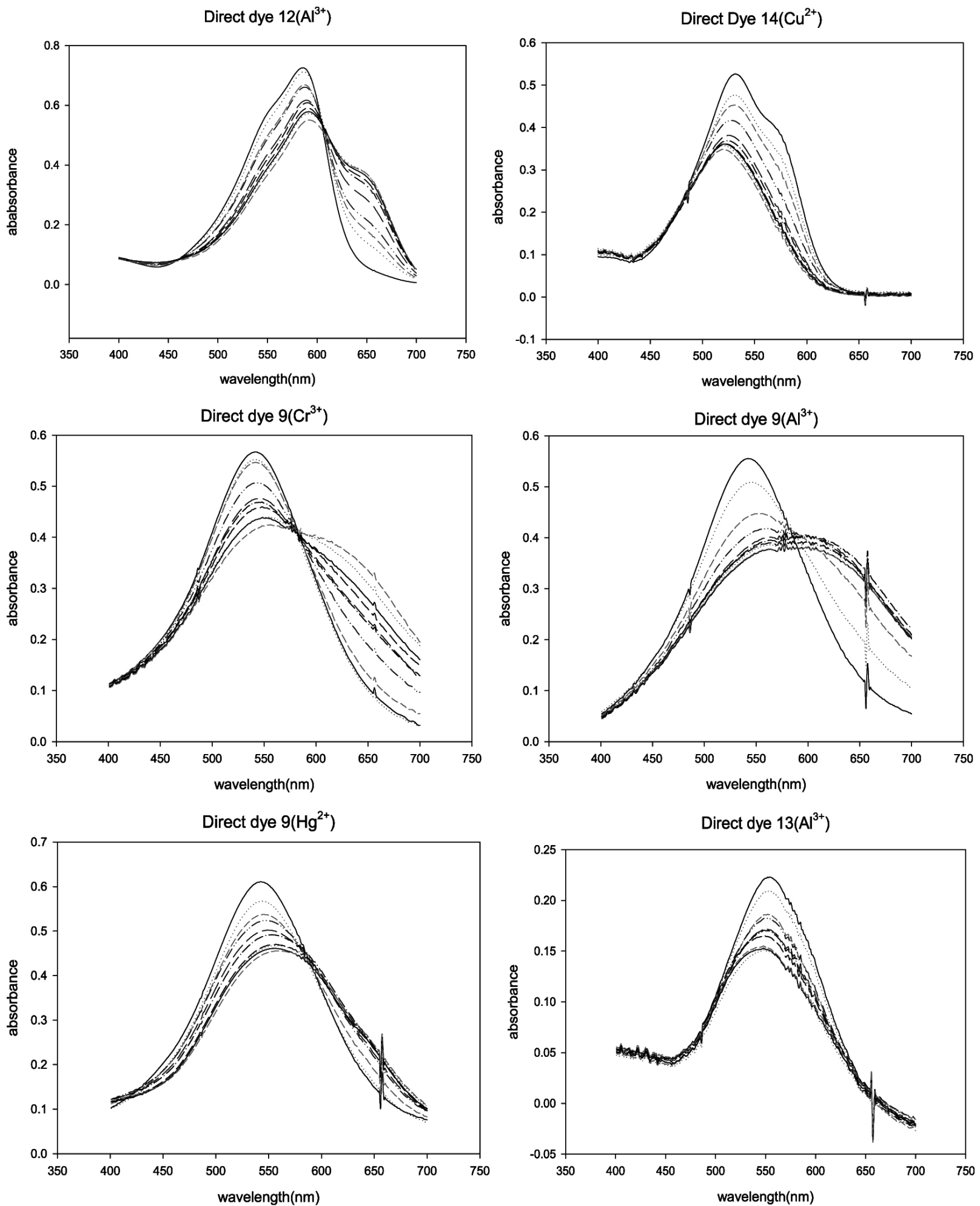

Fig. 7. UV-Vis. spectra of dyes with corresponding metal ion addition. 


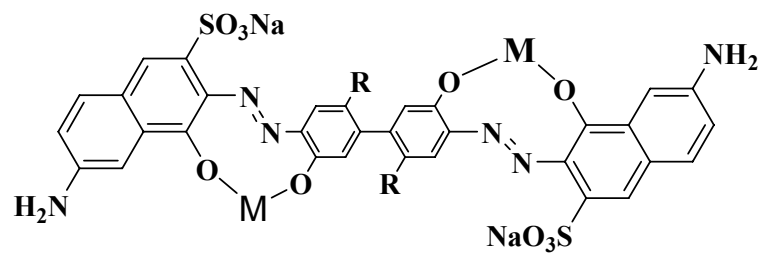

Fig. 8. The formation of ligand for dyes and metals.

\section{Conclusions}

In this study, we prepared new direct dyes using benzidine analogues and various couplers to evaluate as colorimetric chemosensor. The dyes detected several heavy metals such as $\mathrm{Al}^{3+}, \mathrm{Cr}^{3+}, \mathrm{Fe}^{2+}, \mathrm{Fe}^{3+}$, $\mathrm{Hg}^{2+}, \mathrm{Pb}^{2+}$ effectively and selectively in solution state.

\section{References}

1. B. Valeur and I.Leary, Design principles of fluorescent molecular sensors for cation recognition, Coord. Chem. Rev., 205, 3(2000).

2. K. Rurack, Flipping the light switch 'ON' the design of sensor molecules that show cation-induced fluorescence enhancement with heavy and transition metal ions, Spectrochim. Acta, 57A, 2161(2001).

3. A. P. de Silva, H.Q.N. Gunaratne, T. Gunnlaugsson, A.J.M. Huxley, C.P. McCoy, J.T. Rademacher, and T.E. Rice, Singaling recognition events with fluorescent sensors and switches, Chem. Rev., 97, 1515(1997).

4. J.P. Desvergne, A.W. Czarnik, "Chemosensors of Ion and Molecule Recognition", Kluwer: Dordrecht, 1997.

5. A. P. de Silva, D.B. Fox, and A.J.M. Huxley, Combining luminescence, coordination and electron transfer for signaling purposes, Coord. Chem. Rev., 205, 41(2000).

6. A.W. Czarnik, "Fluorescent Chemosensors for Ion and Molecule Recognition", American Chemical Society: Washington, D.C., 1993.

7. O. Malm, Gold mining as a source of mercury exposure in the Brazilian Amazon, Environ. Res., 77, 73(1998).

8. S. Tatay, P. Gavina, E. Coronado, and E. Palomares, Optical mercury sensing using a benzothiazolium hemicyanine dye, Org. Lett., 8, 3857(2006).

9. M. Yuan, Y. Li, J. Li, C. Li, X. Liu, J. Lv, J. Xu, H. Liu, S. Wang, and D. Zhu, A colorimetric and fluorometric dual-modal assay for mercury ion by a molecule, Org. Lett., 9, 2313(2007).

10. M. H. Lee, B. Cho, J. Yoon, and J.S. Kim., Selectively chemodosimetric detection of $\mathrm{Hg}$ (II) in aqueous medis, Org. Lett., 9, 4515(2007). 